\title{
Casamentos de Longa Duração: Recursos Pessoais como Estratégias de Manutenção do Laço Conjugal
}

\author{
Lúcio Andrade Silva - Universidade Federal do Triângulo Mineiro, Uberaba, Minas Gerais, Brasil \\ Fabio Scorsolini-Comin - Universidade Federal do Triângulo Mineiro, Uberaba, Minas Gerais, Brasil \\ Manoel Antônio dos Santos - Universidade de São Paulo, São Paulo, Brasil
}

\begin{abstract}
Resumo
Partindo da abordagem da Psicologia Positiva, este estudo teve por objetivo compreender as principais estratégias e recursos pessoais utilizados por casais engajados em casamentos de longa duração para a manutenção do relacionamento conjugal. Foram realizadas 75 entrevistas com 25 casais heterossexuais unidos, em média, havia 39,48 anos, com média de idade de 64,06 anos. A partir da análise de conteúdo, de frequência e considerando o objetivo do estudo, foram analisadas em profundidade as seguintes categorias: compreensão, comprometimento e doação, espiritualidade e afetividade. Os momentos de crise foram superados, sobretudo, por meio da manutenção dos esforços que cada parceiro envidou, a partir dos seus próprios recursos pessoais e de sua individualidade, contribuindo para o fortalecimento do laço conjugal. Concluiu-se que o casamento é mantido por estratégias que são desenvolvidas tanto a partir de recursos pessoais como de elementos compartilhados pelo par, o que indica que a conjugalidade oferece suporte para sua própria permanência ao longo do tempo.

Palavras-chave: relações conjugais, satisfação conjugal, psicologia positiva
\end{abstract}

\section{Long-term Marriages: Personal Resources as Maintenance Strategies of Conjugal Bond}

\begin{abstract}
Starting from the Positive Psychology approach this study aimed to understand the main strategies and personal resources used by couple engaged in long term marriages in order to maintain the marital relationship. Seventy-five interviews with twenty-five heterosexual couples, together on average for 39.48 years, and aging on average 64.06 years, were performed. Beginning from the analysis of content, frequency, and considering the objective of the study the following categories were analysed: comprehension, compromise and giving, spirituality and affection. The moments of crisis have been overcome, especially by maintaining the efforts that each partner has made, from their own personal resources and their individuality, contributing to strengthening the marital bond. It was concluded that the marriage is maintained by strategies that are developed both from personal resources and elements shared by the couple, which indicates that the conjugality offers support to its own permanence over time.

Keywords: marital relations, marital satisfaction, positive psychology
\end{abstract}

Matrimonios a Largo Plazo: Recursos Personales y Estrategias de Mantenimiento del Vínculo Conyugal

\begin{abstract}
Resumen
A partir del enfoque de la Psicología Positiva, este estudio tuvo como objetivo comprender las principales estrategias y recursos personales utilizados por las parejas comprometidas en matrimonios duraderos para mantener la relación conyugal. Fueron conducidas 75 entrevistas con 25 parejas heterosexuales unidas en promedio hace 39.48 años, con una edad media de 64.06 años. A partir del análisis de contenido, frecuencia y teniendo en cuenta el propósito del estudio, se analizaron en profundidad las siguientes categorías: comprensión, comprometimiento y entrega, espiritualidad y afectividad. Los momentos de crisis se superaron, especialmente mediante el mantenimiento de los esfuerzos que cada cónyuge ha hecho, a partir de sus propios recursos personales y su individualidad, lo que contribuye al fortalecimiento del vínculo matrimonial. Se concluye que el casamiento se mantiene por estrategias que se desarrollan a partir de recursos personales y también de elementos compartidos por la pareja, lo que indica que la conyugalidad ofrece soporte para su propia permanencia a lo largo del tiempo.

Palabras-clave: relaciones maritales, satisfacción marital, psicología positiva
\end{abstract}

No mundo contemporâneo, o casamento ainda é comumente associado à ideia de felicidade, romantismo e laços indissolúveis, o que encontra máxima representação no dito "felizes para sempre". Os momentos de crise, no entanto, são inerentes a esse processo relacional e, na verdade, são até esperados, tendo em vista os eventuais embates na busca de espaço para desenvolver as individualidades de cada parceiro. A percepção positiva ou negativa do conflito provém das habilidades do casal de lidar adequadamente com as divergências, discórdias e desavenças (Fonseca \& Duarte, 2014). Em relação à dinâmica das situações de desequilíbrio conjugal, vários elementos têm sido arrolados como fatores de peso para assegurar o retorno à homeostase temporariamente perdida ou, então, para manter ou agravar o desequilíbrio no relacionamento (Scorsolini-Comin 
\& Santos, 2012; Rizzon, Mosmann, \& Wagner, 2013; Rosowsky, King, Coolidge, Rhoades, \& Segal, 2012; Wagner \& Falcke, 2001).

Sabe-se que, a cada ano, tem aumentado o número de casamentos no país, fenômeno que também vem acompanhado pela ampliação dos divórcios. O crescimento de uniões formalizadas torna-se especialmente importante quando se pensa que o casamento já não é mais considerado como o componente principal do projeto vital dos indivíduos, mas sim um acontecimento evolutivo (Zordan \& Wagner, 2009), e que a vivência do cotidiano familiar e conjugal, nas últimas décadas, propiciou aos casais produzirem novos modos de significações e práticas que se afastam, em alguma medida, das concepções tradicionais (Coutinho \& Menandro, 2010). Além disso, a facilidade que existe atualmente para dissolução dos vínculos, que, na realidade, são permeados de insegurança e fragilidade, e a complexidade envolvida na necessidade de equilibrar as demandas individuais e conjugais simultaneamente (Rogers, 1985) nos relacionamentos estáveis levam os pesquisadores a se questionarem cada vez mais acerca de como os casais podem manter seus relacionamentos por um longo período de tempo, como ocorre nos casamentos de longa duração, ou seja, aqueles com mais de 30 anos de união.

$\mathrm{Na}$ cultura brasileira, falar de casamento é falar de um espaço de afeto. As necessidades afetivas e sexuais são experienciadas de múltiplas formas no seio da conjugalidade e também engendram forças que ajudam a manter a dinâmica conjugal saudável, a despeito das funções primordialmente políticas e econômicas que caracterizaram o casamento por séculos (Coutinho \& Menandro, 2010). Esses autores também apontam que, no contexto nacional, a percepção mais atualizada quanto ao comprometimento no casamento - o lema emblemático "até que a morte nos separe" - perdeu força com o avanço das gerações e o "que seja eterno enquanto dure" vem sendo cada vez mais valorizado como perspectiva de união e de esforço compartilhado para manter os laços conjugais. Os elementos que, no casal, melhor expressam e refletem a estabilidade conjugal são: a decisão de continuarem juntos e o compromisso com a relação, como salientado por Rizzon, Mosmann e Wagner (2013).

O ideal do amor romântico pode se manter em um casamento ao longo dos anos, mesmo que seja despojado do traço obsessivo inicial comum em novos relacionamentos, podendo inclusive ser um fator realçador da vida individual de cada um dos parceiros, positivamente associado à satisfação conjugal, à saúde mental e ao bem-estar geral (Acevedo \& Aron, 2009). Os referidos autores sugerem que o romance em um casamento de longa duração não necessariamente vai minguando, podendo os cônjuges manterem a intensidade, o engajamento e o interesse sexual mútuo. Esse ingrediente romântico pode, inclusive, ser um componente que inspirará o casal a promover mudanças, mesmo que desafiadoras, para melhorar a qualidade da vida conjugal. Nesse sentido, a amizade e o amor são mais do que benefícios auferidos de um relacionamento de longa duração, mas uma de suas causas principais (Bachand \& Caron, 2001).

Um estudo brasileiro mostrou que a necessidade de adaptação também surgiu como essencial à manutenção das uniões de longa duração, ao se considerar que, à medida que a relação avança no tempo, nenhum cônjuge pode permanecer o mesmo (Fonseca \& Duarte, 2014). Em estudo conduzido nos Estados Unidos, percebeu-se que a resolução de conflitos em casamentos com parceiros mais velhos envolve menos emoções negativas e mais carinho entre os cônjuges ao lidarem com o processo conflitual do que se observou em casamentos com parceiros de meia-idade (Carstensen, Gottman, \& Levenson, 1995). Esse achado remete à ideia de que, em casamentos de longa duração, as estratégias de resolução de conflitos modificam-se com o decorrer dos anos, adquirindo um caráter menos destrutivo e mais plástico e positivo. A espiritualidade, entendida como o conjunto de convicções referentes ao significado da vida e à razão de viver, não se limitando a alguns tipos de crenças ou práticas (Fleck, Borges, Bolognesi, \& Rocha, 2003), pode desempenhar papel importante nesse contexto, pois abre espaço para que se fomente uma reflexão que possa englobar as questões existenciais e situacionais. Nesse sentido, a espiritualidade diz respeito à responsabilidade e transformação individual.

Outras pesquisas norte-americanas ainda ressaltam que o coping diádico de suporte é significantemente associado a melhores níveis de satisfação com o relacionamento em casais mais velhos, sendo que a percepção que um dos cônjuges possui dos esforços de coping do parceiro é um preditor importante, associado à sua própria satisfação conjugal e ao entendimento da satisfação conjugal do parceiro (Landis, Peter-Wight, Martin, \& Bodenmann, 2013). Casais envolvidos em casamentos mais satisfatórios e que desfrutam de maior intimidade comumente vivenciam um senso de conforto e bem-estar no relacionamento que reforça suas habilidades 
de reinterpretar positivamente comportamentos de transgressão, o que facilita o processo de identificação com o parceiro ofensor e, em última instância, o perdão e a reparação em relação aos agravos (McCullough, Worthington Junior, \& Rachal, 1997).

Os estudos sobre o relacionamento conjugal, que focalizam os aspectos ligados à satisfação com o casamento, apontam uma multifatoriedade que complexifica o entendimento a respeito do delineamento da vida conjugal ao longo do tempo (Diniz Neto \& Féres-Carneiro, 2010; Karney \& Bradbury, 1995; Norgren, Souza, Kaslow, Hammerschmidt, \& Sharlin, 2004; Rizzon et al., 2013; Wagner \& Falcke, 2001). Percebe-se a necessidade de desenvolvimento de estudos qualitativos sobre as estratégias de resolução de conflitos utilizadas pelos casais, uma vez que a qualidade do relacionamento conjugal é um desfecho composto por diversas dimensões complexas e subjetivas. Resultados eventualmente obtidos com amostra populacional brasileira também são estimados como de extrema relevância para a definição dos programas de intervenção conjugal, tendo em vista que estes se baseiam geralmente em realidades contextuais europeias e norte-americanas (Mosmann \& Falcke, 2011).

Para o estabelecimento de um relacionamento que possa ser considerado satisfatório, Rogers (1985) sugere os seguintes aspectos: (a) dedicação e compromisso; (b) comunicação; (c) dissolução dos papéis; (d) processo de individuação. Os dois primeiros aspectos são corroborados pelos casais entrevistados, de modo que o engajamento parece ser uma característica essencial, que denota o desejo dos cônjuges de permanecerem unidos, não obstante as dificuldades que enfrentam no decorrer dos anos. Segundo Scorsolini-Comin (2014), a última dimensão proposta por Rogers parece ser, à primeira vista, a mais paradoxal, uma vez que, para desenvolver a conjugalidade (o ser "a dois"), é necessário desenvolver o si-mesmo e investir nessa dimensão de crescimento individual. Ao aproximar essa consideração da literatura corrente sobre conjugalidade, mais baseada em modelos psicodinâmicos, considera-se a existência de um espaço conjugal a ser constituído por duas individualidades que se encontram e se misturam; nesse entrelaçamento, produzem uma dimensão psíquica própria, uma "terceira via" criada e nutrida pelo casal. Rogers, no entanto, afirma que o investimento na relação não pode começar por essa dimensão comum, mas sim pelos aspectos trazidos individualmente por cada cônjuge. Essa consideração também é compartilhada pela Psicologia Positiva, que busca o desenvolvimento de recursos pessoais como forma de possibilitar o estabelecimento e desenvolvimento saudável dos relacionamentos interpessoais.

Frente às oscilações entre individualidade e conjugalidade, além das discussões existentes sobre a fragilidade dos vínculos contemporâneos, e pensando que o casamento tende a se modificar ao longo do ciclo de vida familiar, possibilitando alterações na percepção do nível de satisfação dos parceiros, faz-se necessário discutir o modo como os casamentos e as uniões estáveis vêm se desenhando na contemporaneidade (Scorsolini-Comin \& Santos, 2012) e, especificamente, como os enlaces vêm se mantendo no decorrer do tempo.

Especificamente, a presente investigação se propõe a debruçar-se sobre os casamentos de longa duração, ou seja, o relacionamento de casais unidos há mais de 30 anos e que, desse modo, já passaram por diferentes desafios e experiências ao longo do ciclo vital e ao longo do ciclo de vida familiar (Norgren et al., 2004; O’Leary, Acevedo, Aron, Huddy, \& Mashek, 2012; Petrican, Moscovitch, \& Grady, 2014; Rosowsky et al., 2012). As estratégias desenvolvidas por cada cônjuge e pelo par, visando à manutenção do casamento, fazem referência ao modo como cada um consegue identificar os problemas e resolvê-los da melhor maneira possível, visando a um entendimento comum. Essas estratégias traduzem formas de organizar a conjugalidade diante dos desafios inerentes à tarefa de desenvolver-se e de conviver com o outro (Garcia \& Tassara, 2003). A partir dessas considerações e tendo como norte teórico o enfoque da Psicologia Positiva, o objetivo deste estudo foi compreender as principais estratégias/recursos pessoais utilizados por casais engajados em casamentos de longa duração para a manutenção do relacionamento conjugal.

\section{Método}

\section{Tipo de Estudo}

Trata-se de um estudo amparado na abordagem qualitativa de pesquisa, de corte transversal, a partir da perspectiva teórica da Psicologia Positiva. Esse enfoque propõe colocar em evidência os aspectos positivos do ser humano, em um enfoque apreciativo, destacando as potencialidades dos casais para a manutenção do casamento (Scorsolini-Comin, 2014; Scorsolini-Comin \& Santos, 2012).

\section{Participantes}

Foram entrevistados 25 casais heterossexuais, unidos consensualmente (união civil ou estável) havia, 
no mínimo, 30 anos, sem terem se separado e sem estarem em processo de separação conjugal, e com pelo menos um filho. Esses casais são provenientes de cidades do interior dos Estados de Minas Gerais e São Paulo. A descrição das características dos participantes encontra-se na seção de Resultados e Discussão.

\section{Instrumentos}

Foram empregados os seguintes instrumentos: (1) técnica da história oral de vida, para permitir uma expressão da memória que valoriza o modo singular de construção das histórias e das experiências de cada indivíduo (Meihy, 2006); (2) entrevista semiestruturada com cada cônjuge; (3) entrevista semiestruturada com o casal; e (d) diário de campo, um modo complementar de observar a interação e o comportamento dos cônjuges no momento das entrevistas.

O presente estudo foi delineado em resposta a uma questão mais ampla, relacionada às transformações da conjugalidade ao longo do tempo nesses arranjos conjugais, em que foi possível observar a importância dos recursos pessoais na manutenção do casamento. As entrevistas foram guiadas por um formulário construído pelos próprios autores e tiveram o intuito de possibilitar colher informações básicas, tais como idade, escolaridade, religião e número de filhos, além de abranger questões como a transição da vida de solteiro para a vida de casado, a construção da intimidade do casal e as estratégias utilizadas pelo par para enfrentar os desafios e dificuldades da vida a dois. Os roteiros de entrevista semiestruturada continham alguns tópicos que se repetiam em ambas as entrevistas (individual e na presença do cônjuge), com a finalidade de verificar se a presença ou ausência do parceiro promoveria variação nas respostas.

\section{Procedimento}

Coleta de Dados. Os potenciais participantes foram abordados a partir de contatos da rede social dos pesquisadores. Após a assinatura do Termo de Consentimento Livre e Esclarecido deu-se início às entrevistas, realizadas uma única vez com cada casal. Inicialmente, entrevistou-se cada cônjuge separadamente e, em seguida, realizou-se a entrevista com ambos, resultando em um total de três entrevistas por casal, inteirando 75 entrevistas. Todas as entrevistas foram transcritas na íntegra e literalmente para a composição do corpus deste estudo.

Análise dos Dados. $\mathrm{O}$ corpus foi submetido à análise de conteúdo, a partir do método descrito por
Bardin (1977/2010). Trata-se de um conjunto de técnicas de análise das comunicações, que consiste em um leque de recursos que confluem para um mesmo fim: o de avaliar heurística e inferencialmente o interdito da comunicabilidade humana. Nesse caso, diz respeito a uma descrição analítica dos significados, que é o tratamento das informações contidas nos discursos de modo temático. Após a leitura minuciosa dos relatos dos participantes, foram elencados os recursos pessoais mencionados como importantes para a manutenção do casamento. Tais recursos, posteriormente, foram agrupados em categorias conforme semelhanças e convergência temática. Essas categorias foram, então, quantificadas em termos de frequência, expressas pelas menções nas entrevistas, tanto nas entrevistas individuais como nas de casal. Depois dessa quantificação e do objetivo do estudo, foram analisadas em profundidade as quatro categorias consideradas mais significativas, a partir das falas. Por fim, as categorias foram analisadas segundo a perspectiva da Psicologia Positiva.

\section{Considerações Éticas}

Este estudo foi aprovado pelo Comitê de Ética em Pesquisa da instituição de origem dos autores (Processo 2011/1936).

\section{Resultados}

Em relação ao perfil sociodemográfico, a maior parte dos participantes pertencia às camadas médias da população do interior dos estados de São Paulo e Minas Gerais, concluiu pelo menos a terceira série do ensino fundamental e era adepta ao catolicismo ou espiritismo. Os cônjuges tinham média de idade de 64,06 anos (DP =13,26). A idade mínima dos participantes foi de 51 anos e a máxima de 82 anos. Os casais estavam unidos havia 39,48 anos em média $(D P=6,76)$ e tinham em média 3,48 filhos $(D P=1,58)$. Todos os casais tinham pelo menos um filho. $\mathrm{O}$ menor tempo de união observado foi de 32 anos e o maior, 53 anos.

A análise de conteúdo temática originou sete categorias de estratégias/recursos utilizados para a manutenção do relacionamento conjugal, que foram agrupadas de acordo com a frequência de incidência (menção) nos relatos dos entrevistados: compreensão $(f=86)$, comprometimento e doação $(f=46)$, desenvolvimento de hábitos ou comportamentos individuais $(f=30)$, espiritualidade $(f=21)$, afetividade $(f=16)$, necessidade de adaptação $(f=8)$ e humildade $(f=3)$. 
No presente estudo, optou-se por restringir a discussão às quatro categorias que se mostraram mais significativas em termos de importância para alcançar o objetivo do estudo, a saber: compreensão, comprometimento e doação, espiritualidade e afetividade. Apresentando brevemente as outras categorias, tem-se que o desenvolvimento de hábitos ou comportamentos individuais refere-se à aquisição de novos hábitos ou comportamentos ao longo do casamento por um dos parceiros, tais como apoio para enfrentar as oscilações do cotidiano conjugal e do cotidiano pessoal, considerando que os comportamentos ou hábitos cotidianos de ambos influenciam-se mutuamente e envolvem o amadurecimento emocional, a resiliência e a abdicação de alguns hábitos, como a ingestão excessiva de bebidas alcoólicas, em prol do bem-estar conjugal. A Necessidade de adaptação engloba o discurso de que o tempo de relacionamento progride concomitantemente ao aprendizado que cada um dos parceiros extrai das dificuldades encontradas nas distintas situações de vida, o que se reflete em movimentos de flexibilidade para deixar a zona de conforto e em mudanças de cenários. Por fim, a categoria Humildade diz respeito à habilidade desenvolvida pelo cônjuge de admitir-se imperfeito, adquirir consciência de suas limitações e ter sabedoria para perceber que sempre é possível aperfeiçoar aspectos e características pessoais e, assim, melhorar a qualidade do vínculo conjugal pela disposição de se reinventar como pessoa e como parceiro(a).

\section{Categoria 1: Compreensão}

Essa categoria agrupa as referências encontradas nos relatos dos participantes que dizem respeito à resignação, aceitação, paciência, tolerância, diálogo, sinceridade, silenciamento, ou uso de verbos, como ceder, concordar, conciliar, pedir perdão, com significado de contemporizar, condescender, transigir, compor-se e contemporizar diante de posições antagônicas, com 86 menções ao todo, 44 (51,16\%) delas por parte das esposas, $25(29,07 \%)$ por parte dos maridos e $17(19,77 \%)$ por ambos os cônjuges. Esses relatos dos casais entrevistados abrangem, em sua totalidade, o aspecto crucial que é a alcançar a compreensão em um relacionamento a dois, especialmente nos de longa duração. Os casais admitem não ser fácil conviver com uma outra pessoa, com suas idiossincrasias e seu jeito peculiar de ser, por mais de 20 ou 30 anos, sem que essa convivência diária afete a própria individualidade. Nesse caso, a compreensão tem um papel de manter os aspectos positivos do casamento frente às disparidades e diferenças individuais. O excerto de fala a seguir reflete esses desafios.

Você entende a pessoa. Você entende ela. Então: "Ah, esse prato não pode ficar aqui", "Tudo bem, onde você quer que fica?", "De cá". Sabe, essa coisa assim, de entender? Mas entender não é recalcar. É libertar pra melhorar, pra mudar. Marido 12)

Compreender é (re)conhecer a individualidade do parceiro, entendê-lo a partir do seu próprio ponto de vista. É um fluxo de intenções que parte de um cônjuge em direção ao outro para facilitar a convivência e manter o laço conjugal estável, inclusive mobilizando ao diálogo e à comunicação para esclarecer o atual estado do relacionamento e possibilitar a mudança de comportamentos disfuncionais para que se possa restabelecer o entendimento quando a estabilidade estiver ameaçada. Sem aceitação empática do ponto de vista do outro a estabilidade do laço conjugal pode ficar comprometida, o que muitos casais relatam como sendo o principal motivo que predispõe ao término do relacionamento.

A compreensão é um componente de cada cônjuge que atua na prevenção de conflitos que podem fustigar e desgastar o relacionamento conjugal, contribuindo para que haja uma reflexão individual por parte de um dos cônjuges sobre o seu modo de ser no cotidiano conjugal, o que permite que ele meça as próprias palavras, ações e atitudes, comparando-as com o cenário atual do relacionamento. Isso tira o foco da culpabilização do outro e faz o cônjuge perceber a sua (co)participação nesse cenário, mobilizando-o para a mudança a partir da ativação de suas habilidades de comunicação.

Nós temos que saber enfrentar os momentos de crise, né? Em todo relacionamento. [...] E ai nós temos que saber exercer algumas situacões de tolerância, de paciência, né? De... de compreensão. E, muitas vezes, até de renúncia, sabe? [...] Porque se você não conseguir faz̧er isso... eu acredito que... vai começar a entrar em uma crise maior, né? (Marido 13)

Os conflitos são inerentes à natureza dos relacionamentos amorosos. Os casais afirmam que a chave para o enfrentamento das divergências é encontrada no exercício cotidiano da tolerância mútua, com paciência, aceitação e, por vezes, até com renúncia e resignação, elementos que facilitam a vivência desses momentos "em favor do outro", conforme relatou o Marido 13. Saber compreender o outro exige aprendizado por intermédio do relacionamento, pois envolve perceber o eixo de atuação do parceiro segundo as referências 
do outro e não de acordo com suas próprias crenças. Procurando desenvolver essas disposições, o cônjuge consegue suportar as turbulências na passagem por situações complicadas no relacionamento a dois, além de evitar a reincidência de conflitos no futuro.

A compreensão, por vezes, pode ser expressa de um modo diferente da intenção consciente demonstrada por um parceiro para (re)conhecer e compreender a perspectiva do outro. Às vezes, ela se manifesta no movimento contrário: ao invés de se dirigir para o outro, direciona-se para si mesmo, resultando em um movimento introspectivo de silenciamento e resignação. Para arrefecer os conflitos momentaneamente, pode ser necessário não reagir sob nenhuma circunstância, adotando a tática do silenciamento ou do não confrontamento e a imersão na própria interioridade, para somente depois dirigir-se ao parceiro para procurar entender suas razões. A busca de uma posição moderadora é valorizada pelos cônjuges.

\begin{abstract}
Ah, eu acho que é essa tolerância, né? Aceitar. Aceitação, né? Porque as pessoas são diferentes. [...] Então você... eu acho que o amor é isso, né? Você estar aceitando a outra pessoa do jeito que ela é. A gente tem aquele impulso de querer mudar... moldar [risos] do jeito que a gente acha que seria o bom, o perfeito, como en queria que fosse. Mas eu acho que aceitação, o entendimento de você saber que a outra pessoa é ela, assim, cheia de defeitos, de qualidades, de sonhos, de... né, que são dela. E você precisa aceitar isso pra você ter um relacionamento duradouro. [...] que você respeite a outra pessoa com todas as suas limitaçôes. (Esposa 13)
\end{abstract}

Por fim, percebeu-se que a compreensão envolve também o manejo de recursos pessoais próprios de cada cônjuge, que se mostram imprescindíveis para a preservação do equilíbrio no relacionamento conjugal, como as fantasias, idealizações, inspirações e sonhos que cada um leva para enriquecer o convívio do casal. Compreender vai além de apenas (re)conhecer os limites e as potencialidades do parceiro, pois envolve a manutenção da própria individualidade para adequar-se à realidade conjugal. É um ajustamento sem subserviência, adaptação ativa em vez de submissão passiva.

Sem a mudança de perspectiva sobre o que é o cotidiano conjugal não é possível sustentar a convivência com aquele(a) que é diferente. Também se constatou que, quando se espera a mudança por parte do outro cônjuge em relação a algum aspecto, é possível que aquele que nutre essa expectativa também precise mudar, ainda que ele não tenha percebido prontamente essa necessidade. A exigência ("cobrança") quase sempre é bidirecional, ou seja, ambos precisam moldar-se à singularidade do outro.

\section{Categoria 2: Comprometimento e Doação}

Referências à necessidade de comprometimento e doação foram mencionadas 46 vezes nas entrevistas e, desse total, $16(34,78 \%)$ foram identificadas nos relatos das esposas, $22(47,83 \%)$ apareceram no discurso dos maridos e oito $(17,39 \%)$ nas falas dos casais.

Parece que as coisas que a gente tem, com o passar dos anos, viram uma rotina, né, mas a gente tem que transformar isso em amor, carinho e sempre dando, assim, um incentivo, né? (Marido 5)

A gente tem que fazer por onde viver o casamento, por onde ter o casamento, porque o casamento é assim, tipo uma alimentação. Cê tem que sempre alimentar ele. Sempre ocê não alimenta o seu estômago, todo dia cê não come, todo dia cê não toma café, cê almoça, cê janta? Então é igual seu casamento. (Esposa 16)

Um dos elementos mais expressivos, dentre os elencados como essenciais para manutenção do casamento de longa duração, foi a doação. A rotina e as inúmeras demandas que a vida impõe aos cônjuges podem cristalizar o vínculo conjugal como um apêndice das suas próprias vidas e, por isso, torna-se imprescindível o espírito de doação e renúncia para o fortalecimento do laço conjugal, entendido mais como uma atitude constante do que como uma disposição pontual.

Esposa 12: Hoje em dia o casamento é visto como uma coisa não muito séria. Eu vejo assim, o casamento assim... ninguém é... pensa nele como ele deveria ser pensado, vê ele como ele deveria ser visto. Porque é uma coisa séria. Você não pode entrar nele pensando assim: "Se não der certo, eu saio fora". Pelo contrário, se não der certo, eu tenho que fazer tudo para aquilo dar certo.

Marido 12: Lutar, né? É renúncia.

Esposa 12: Não que eu ache que o casamento não possa ser desfeito, mas é a última... é a última... da etapa que você tem que... enfrentar, é a separação. Depois que você lutou com todas as armas que você tinha. (Casal 12)

Quando questionado a respeito de como era a percepção social do casamento na época em que se casaram, o casal $12 \mathrm{fez}$ apontamentos sobre como a questão do comprometimento e da responsabilidade é 
vista diferentemente pela sua geração e pelas pessoas mais jovens engajadas em relacionamentos estáveis. Essa questão tangencia a discussão do zeitgeist contemporâneo de liberdade e individualidade, noções que têm seus limites reconfigurados na vida a dois, representados pela ideia de: "Ah não, se não der certo, cada um procura seguir sua vida.”. Em um casamento de longa duração, essa ideia é inconcebível, e todos os casais entrevistados relataram um idêntico ponto de vista sobre o assunto: casamento duradouro necessita de disposição autêntica para renovar o compromisso. Os termos proferidos no altar, como "Até que a morte nos separe", são apreciados com seriedade pelos casais católicos de longa duração, e definitivamente contribuem para sustentar a atitude de fazer perseverar a união, mesmo com todas as dificuldades impostas pelas circunstâncias de vida.

\section{Categoria 3: Espiritualidade}

A categoria Espiritualidade foi composta por 21 menções identificadas nos relatos dos entrevistados, com 14 apontamentos por parte das esposas $(66,67 \%)$, cinco por parte dos maridos $(23,81 \%)$ e dois pelo casal $(9,52 \%)$. A espiritualidade pode atuar na manutenção do laço conjugal como um elemento de apoio e até de refúgio para um dos parceiros no enfrentamento de situações conflituosas, como referido pela Esposa 1. Em momentos nos quais não se tem a quem ou a o que recorrer, a espiritualidade é apontada como um dos pontos de apoio mais significativos, pois se relaciona com a esperança de que dias melhores virão: "Só Deus. A busca de Deus. É, quer dizer, Deus é um pensamento, né, como Deus é um pensamento, porque ninguém conhece Deus, então você busca Ele, né, e quando você busca Ele, você tem um apoio" (Marido 18).

A mesma ideia também é reportada pelo Marido 18, quando questionado: "Durante os momentos dificeis, o que para você é uma fonte de apoio, uma fonte de ajuda? O que ajuda você a passar por isso?". Esse participante acrescenta ainda a fé e a positividade da busca por algo que sirva para legitimar as tentativas de perseverar.

Como é que vocês acham que conseguiram enfrentar isso? [...] Eu acho que... é uma coisa por Deus... Porque... tudo é difícil. Uma vida a dois é muito difícil, mas a gente segurou na mão de Deus e está onde está... Porque a gente não pode desesperar e, no primeiro tombo a gente achar que não tem jeito mais. Isso ai é uma bobagem. Tem que aguentar as pontas. (Esposa 10)

A Esposa 10 também comenta, ao responder a uma pergunta acerca de como ela conseguia enfrentar momentos difíceis no casamento, sobre a necessidade de manter uma atitude resiliente e perseverante, intimamente conectada aos conhecimentos e à filosofia de vida proporcionados pela espiritualidade.

\section{Locê acha que obteve outras fontes de ajuda, durante esses momentos difíceis?] Ah, acho que religião ajuda bastante, né? Você ter um ponto de apoio, ter certos conbecimentos [...] Acho que a doutrina espirita traz. muito dessa realidade, desse conhecimento, né? [...] É... tem sido em função até da própria fé que a gente tem, da própria crença que a gente absorveu, através da religião que a gente segue, da filosofia que a gente segue, e... Que nos dá uma visão diferente da vida, né? (Esposa 13)}

A Esposa 13 também aponta a gama de conhecimentos que a espiritualidade proporcionou como novos modos de se perceber, valorizar e enfrentar as situações consideradas difíceis da vida, notadamente as do casamento, compactuando com o pensamento de que, na verdade, as situações consideradas difíceis são efêmeras e que a união entre os desempenhos individual e do casal pode contribuir para superar as adversidades em prol do equilíbrio do relacionamento afetivo.

Agora nós começamos a ser ministro da eucaristia [...] uniu mais ainda a gente, porque eu acho assim, a religião também ajuda demais, né? A gente tava na nossa vida assim, a gente ia à missa... Voltava... Ficava o marasmo... Ai, de repente, o padre chegou, chamou a gente, nós fomos participar, fizemos, tem reunião, tem muita coisa, fizemos muita coisa... (Esposa 19)

Desse modo, a Esposa 19 aponta uma outra potencial contribuição da espiritualidade na manutenção do relacionamento conjugal: a abertura de novos espaços a serem frequentados pelo casal. A espiritualidade, frequentemente, permite o acesso a uma vasta rede social interconectada por meio dos serviços religiosos, que possibilita aos adeptos a imersão em novos cenários, contribuindo para a troca de conhecimentos e experiências com pessoas novas. Essa situação renova o cenário do laço conjugal e protege o casal da estagnação decorrente da rotina. Além disso, acrescenta pontos de encontro e permite a diversificação de vivências no casamento, mantendo-o conectado e atualizado com a dinâmica do mundo.

\section{Categoria 4: Afetividade}

Nessa categoria foram consideradas as menções a aspectos relacionados ao afeto, carinho, cuidado, zelo, 
respeito, companheirismo e apoio emocional. Foram identificadas 16 alusões a esses elementos, sendo 10 delas por parte das esposas $(62,5 \%)$ e seis por parte dos maridos $(37,5 \%)$. Os trechos a seguir indicam como os participantes compreendem a importância da afetividade na manutenção do casamento.

É esse afeto, esse carinho que a gente tem um pelo outro... E, acima de tudo, o respeito, né? Eu acho que é isso... Cumplicidade. É uma coisa de muitos anos, né? Aquela coisa de você olhar e só de você bater o olho já saber se tem, se tá com problema, se tá sentindo uma dor, né? Se tá contrariado. Cê entendeu? Tudo isso cê bate o olho e já sabe, né? 'O que foi? O que aconteceu?'." (Esposa 9)

Nota-se, na resposta da Esposa 9 à pergunta "Apesar das dificuldades do dia a dia, o que você considera importante pra se manter casada?", que o envolvimento afetivo vai muito além de simples atos ou demonstrações de carinho e preocupação por parte do outro cônjuge. De fato, transcende os limites do visível e do tangível, alcançando um nível de (re)conhecimento extremamente íntimo do casal. A intensidade da cumplicidade alcançada pelos cônjuges, que foi e que vem sendo construída continuamente ao longo dos anos pela interação e convivência cotidiana, possibilita que isso aconteça, refletindo uma sintonia fina que permite a imediata identificação do estado de espírito do parceiro, o que dispensa inclusive a necessidade de empregar palavras para se comunicar.

É notável também o movimento que essa afetividade faz gerar no seio da relação, provocando direcionamentos e predisposições de um cônjuge em relação ao outro, como dito pela Esposa 9: "O que foi? O que aconteceu?". O afeto mobiliza forças e energias que fazem com que um cônjuge perceba e (re)conheça o seu companheiro como alguém que necessita de atenção, contribuindo para o ativação de outros aspectos que são essenciais na manutenção dos laços conjugais, como a compreensão e a habilidade de comunicação.

Essa cumplicidade, né? Essa cumplicidade que far parte de um... né? Já... eu não poderia dizer uma alma gêmea... porque a gente também não acredita nisso, numa alma algemada, né? Almas algemadas nem almas gêmeas, né? Mas essa cumplicidade, um aprendeu a confiar no outro, um aprendeu a respeitar o outro, a já conbecer, né? (Marido 13)

A cumplicidade mais uma vez é indicada como um elemento catalisador do (re)conhecimento conjugal, compondo a consciência que um parceiro tem do outro no sentido de entender e até de "antever" as suas reações e atitudes, mesmo as mais corriqueiras. Essa cumplicidade não é percebida como um aprisionamento, diferentemente do que muitos pensam sobre o casamento. $\mathrm{Na}$ verdade, ela é um esforço que se origina em cada um dos cônjuges e que, por isso, constitui-se como um elemento bidirecional que contribui para o estreitamento do laço conjugal, sendo percebida mais como uma atitude que predispõe à vinculação.

\section{É o que nós falamos, né? A receita é você procurar se modifi- car você mesmo, né? Do como você enxerga e como você reage com o seu próximo, seja ele quem for... Então, esse que é o segredo de um casamento longo. E pra fazer isso tem que ter amor, senão... Se não tiver amor, você não consegue fazer isso. (Esposa 13)}

A cumplicidade, então, só contribui de fato para a união de longa duração quando o (re)conhecimento de um parceiro possibilita a modificação das próprias reações do outro, no sentido de (re)conhecer para (re) agir na mesma sintonia. E o amor, visto como símbolo máximo da afetividade entre duas pessoas, é percebido como essencial para a manutenção da harmonia conjugal, uma vez que ele envolve sentimentos de tolerância, paciência, compreensão e renúncia, como apontado pela Esposa 13.

Eu acho que, através do amor, do carinho, né, da compreensão, porque... casamento... não é só sexo, é claro que tem que ter, né, no casamento, mas não é só isso não. [...] Eu acho que agora... acho não, tenho certeza que a gente se ama mais do que no começo. Eu acho que, do começo do namoro, dos primeiros anos de casamento, eu acho que era paixão. $O$ amor vem sendo construido com o tempo, aí vira um amor muito sólido. (Esposa 14)

[...] porque tem que ter mais, assim, pra conviver tem que ter mais carinho com o outro, dar mais atenção... Tanto eu dar atenção como ele dar atenção pra mim, porque se a gente não viver dando atenção ao outro, como é que a gente convive? Ai aquele amor vai esfriando, vai acabando, depois vai perdendo aquele amor que construiu por quanto tempo, né? (Esposa 16)

Percebe-se que o intercâmbio sexual também é considerado como sendo muito significativo para a solidificação da cumplicidade, mas que elementos como respeito, carinho, consideração e disposição são valorizados como sendo muito mais importantes para a constituição de uma vida conjugal sólida. Como apontado pelas Esposas 14 e 16, a natureza do casamento 
vai mudando com o passar dos anos, e o amor, entendido como uma paixão no início do relacionamento ou como uma força mais intensa, porém destituída inicialmente dessa harmonia da cumplicidade, é apontado como sendo o principal combustível que mantém acesa a chama e o principal recurso que solidifica as bases do vínculo conjugal. Nota-se que o sentimento amoroso é percebido como um fenômeno que vai sendo construído e mantido ao longo do tempo, o que nos autoriza a compreendê-lo como uma noção que aponta para a permanência daquilo que, apesar das mudanças inerentes ao viver, continua a vincular os cônjuges.

\section{Discussão}

Os recursos empregados pelos participantes para a manutenção do casamento em uniões de longa duração revelam movimentos que se estruturam ora em torno de aspectos individuais, ora em termos de elementos do par, desenvolvidos de modo conjunto. Essa complexidade é considerada inerente à noção de conjugalidade, que se apresenta como uma dimensão psíquica habitada, estruturada e permanentemente nutrida pelo casal e suas individualidades (Diniz Neto \& Féres-Carneiro, 2010).

A afetividade emerge como um dos recursos construídos pelo casal ao longo do tempo no solo compartilhado da conjugalidade. Embora essa afetividade possa encontrar uma manifestação individual, é no contexto da relação conjugal que ela é fortalecida e pode justificar a permanência do carinho, do respeito mútuo e também do desejo pelo outro ao longo do tempo, como demonstrado na Categoria 4.

A compreensão, embora esteja relacionada ao modo como o outro reage, parece ser um recurso que depende mais de aspectos individuais, desenvolvidos como favorecedores da tolerância, paciência e, em certos casos, resignação frente ao que não se pode mudar, em função do contato com o outro, que se mostra e se comporta de modo diferente do esperado, o que ficou claro na Categoria 1. Por tolerância, entende-se o reconhecimento do direito do outro de ter pontos de vista diferentes ou até diametralmente opostos aos nossos. É a permissão concedida ao outro para ser o que ele é e também uma disposição dos que sabem ouvir com paciência opiniões opostas às suas. $O$ senso que um indivíduo tem de si próprio.

Compreender as diferenças remete tanto à gestão de conflitos (Mosmann \& Falcke, 2011) e ao modo individual de percebê-los como negativos ou positivos
(Fonseca \& Duarte, 2014), como à aceitação de gostos e hábitos muito distintos dos próprios. Essas capacidades estão diretamente relacionadas à coesão e consistência da própria identidade, isto é, o senso que o indivíduo tem de si próprio. A compreensão é também balizada pela espiritualidade dos parceiros, como apontado pelos entrevistados na Categoria 3, constituindo-se como um ponto de apoio para além do casamento para uma eventual supressão dos eventos negativos da conjugalidade e da vida ou para a manutenção da estabilidade conjugal.

Como proposto por Seligman (2011), o bem-estar é composto (e também promovido) por cinco fatores: emoção positiva, engajamento, sentido, relacionamentos positivos e realização. Como se pode observar nos achados do presente estudo, os recursos pessoais empregados e desenvolvidos fazem referência direta a esses elementos. Transpondo essas considerações acerca do bem-estar para a noção de satisfação conjugal, há que se compreender, por exemplo, que o investimento pessoal em uma relação de casal requer a potencialização de aspectos como o engajamento, haja vista que este pode ser o fator que contribui para a continuidade da relação ao longo do tempo, o que é corroborado pelos casais, especialmente na Categoria 2. A própria conjugalidade pode ser veículo para a conquista de um relacionamento positivo, considerado pelo sujeito como relevante para a obtenção de realização pessoal, de modo que se pode relacionar diretamente bem-estar e satisfação conjugal, a exemplo do que foi evidenciado em outros estudos (Schlösser, 2014; Scorsolini-Comin \& Santos, 2012). Além do sentimento de bem-estar, Acevedo e Aron (2009) apontam a importância e a permanência da mutualidade sexual entre os parceiros ao longo do tempo como motivadores da melhora da qualidade conjugal, fator também ressaltado pelos participantes do presente estudo.

A relação entre bem-estar e satisfação conjugal também foi percebida na utilização de estratégias para manutenção da estabilidade conjugal nos casais longevos entrevistados, como também foi apontado pelos estudos de autores estadunidenses como Landis, Peter-Wight, Martin e Bodenmann (2013) e de McCullough, Worthington e Rachal (1997). Esses autores ressaltaram que a conjugalidade também é preditora de elementos e recursos que catalisam o esforço e o comprometimento no sentido de preservar o relacionamento ao longo do tempo e das imprevisibilidades da vida. Rizzon et al. (2013) apontam para a mesma direção quando afirmam que o compromisso e o engajamento com a relação são 
os elementos que melhor expressam a estabilidade conjugal. São dados que corroboram a hipótese proposta por Coutinho e Menandro (2010) de que razões afetivas e sexuais acabam por mobilizar forças que mantêm a dinâmica conjugal saudável. A conjugalidade parece fornecer elementos de apoio e conforto que acarretam movimentos dos parceiros para mantê-la estável, e vice-versa.

$\mathrm{Na}$ abordagem humanista, predecessora da Psicologia Positiva, Rogers (1985) destaca a necessidade de que cada cônjuge desenvolva, individualmente, a sua autoaceitação, podendo, a partir disso, abrir-se à experiência do outro. Tal aspecto se relaciona ao que os participantes destacaram quanto à necessidade de compreender e acolher o outro, uma aptidão para consentir que fomenta a tolerância e a aceitação. Esse outro, o cônjuge, é colocado em uma posição de diferente, como alguém que se comporta e se expressa de maneiras distintas em relação ao parceiro. Essas diferenças, no entanto, não precisam ser compreendidas como algo que poderia afastar os casais, mas sim uni-los diante da experiência do contato com o diverso, o que, quando bem integrado pelos cônjuges, proporciona aprendizado, trocas e enriquecimento mútuo. Assim, para Rogers (1985), o movimento necessário para a estruturação da conjugalidade é que a pessoa aceite incondicionalmente a si própria em suas dificuldades, fragilidades e limitações, podendo, posteriormente, aceitar essas dimensões em seu parceiro, o que promove uma união mais autêntica.

$\mathrm{Na}$ terapia de casal baseada na abordagem da Psicologia Positiva, um dos exercícios mais importantes é o do fortalecimento das capacidades e recursos pessoais (Scorsolini-Comin, 2014). Cada cônjuge deve ter consciência de suas capacidades e do modo como elas podem ser úteis tanto para resolver possíveis conflitos, como para facilitar o estabelecimento de relacionamentos satisfatórios. (Re)conhecer-se, conforme se observou nas entrevistas realizadas com os participantes do presente estudo, é um gesto de autorreflexão e de autoposicionamento no casamento que contribui para sustentar um relacionamento satisfatório, corroborando Rogers (1985). A capacidade de tolerar, empatizar-se com o outro e de se comunicar de modo aberto são recursos pessoais que, uma vez empregados no contexto conjugal, favorecem o entendimento e a adoção de posturas mais adequadas. Conhecer e reconhecer esses recursos pessoais são movimentos fundamentais na clínica de família e casal, já que as pessoas se dedicam muito pouco ao exercício de se olharem profundamente, buscando o reconhecimento das próprias potencialidades (Seligman, 2011).

Evidentemente, a mera observação das frequências das menções por parte das esposas, dos maridos e do casal não permite tirar conclusões acerca da população estudada. Novos estudos devem ser conduzidos para sustentar qualquer pressuposto, como a existência de possíveis diferenças decorrentes das assimetrias sociais e de gênero, bem como das trajetórias dinâmicas da conjugalidade. Entretanto, com base nos dados obtidos, cabe apontar que os maridos valorizaram mais a compreensão mútua, enquanto que as esposas valoraram mais a afetividade. Isso pode ter relação com o cenário ideológico da época em que se desenvolveram e se casaram, quando o marido se identificava mais com o papel de provedor material no casamento e a esposa se relacionava mais com os aspectos sensíveis e emotivos, direcionados para o exercício dos cuidados com a casa e a prole. Notou-se também que a Categoria 4 não foi mencionada em nenhum relato pelos parceiros ao mesmo tempo, mas isso pode ser devido ao procedimento metodológico da entrevista com ambos os cônjuges.

O presente estudo evidenciou os principais recursos empregados por cônjuges para a manutenção dos relacionamentos afetivos longevos. Entre as limitações da pesquisa, deve-se destacar que esses recursos foram evidenciados em resposta à questão mais ampla das transformações da conjugalidade ao longo do tempo em casais de longa duração, e que estudos posteriores focalizados especificamente na temática dos recursos pessoais poderão expandir as possibilidades de entendimento da dinâmica conjugal. A utilização de instrumentos que propusessem aos cônjuges a necessidade de resolver conflitos ou situações problemáticas, por exemplo, poderia contribuir no sentido de evidenciar mais claramente tais recursos e estratégias. A literatura científica escassa na área, notadamente no contexto nacional, dificulta o estabelecimento de comparações com outras investigações.

Os relatos analisados mostraram que, muitas vezes, os cônjuges lançam mão de recursos que são adquiridos ou desenvolvidos ao longo da vida para enfrentar os desafios e conflitos do casamento. Não só as provocações do casamento, como também as dificuldades individuais, considerando que essas reverberam no modo como cada cônjuge se conduz na relação conjugal e, de um modo mais extenso, na relação familiar. Nesse sentido, as dificuldades e experiências individuais de cada parceiro, vivenciadas a longo da vida, 
são indiretamente contribuintes para o equilibrio ou desequilíbrio conjugal. Acima de tudo, a afetividade, a compreensão, a espiritualidade, o desenvolvimento de recursos individuais, a necessidade de adaptação, a humildade e o comprometimento e doação foram apontados como recursos para auxiliar a manutenção do jogo no qual "um e um são três" (Diniz \& Féres-Carneiro, 2010). Foram esses os ingredientes que, no entendimento dos casais longevos, contribuíram para que as duas individualidades unidas pelo laço conjugal perseverassem frente às oscilações da vida, mantendo-se com vigor e vitalidade por tantas décadas.

Ainda que se tenha discutido a incidência dos recursos pessoais de modo categórico, percebeu-se o quanto os elementos elencados como essenciais à manutenção do laço conjugal frente aos desafios da vida são de fato imbricados e articulados, não podendo ser compreendidos isoladamente. Além disso, a teia conjugal é mantida por estratégias que são desenvolvidas e transformadas tanto a partir de recursos pessoais, como de elementos compartilhados pelo par, o que sugere que a conjugalidade oferece suporte para sua própria permanência ao longo do tempo.

\section{Referências}

Acevedo, B. P., \& Aron, A. (2009). Does a long-term relationship kill romantic love? Review of General Psychology, 13(1), 59-65. doi: 10.1037/a0014226

Bardin, L. (1977/2010). Análise de conteúdo (L. A. Reto \& A. Pinheiro, Trads.). Lisboa: Edições 70.

Bachand, L. L., \& Caron, S. L. (2001). Ties that bind: A qualitative study of happy long-term marriages. Contemporary Family Therapy, 23(1), 105-121. doi: 10.1023/A:1007828317271

Carstensen, L. L., Gottman, J. M., \& Levenson, R. W. (1995). Emotional behavior in long-term marriage. Psychology and Aging, 10, 140-149. doi: 10.1037/0882-7974.10.1.140

Coutinho, S. M. S., \& Menandro, P. R. M. (2010). Relações conjugais e familiares na perspectiva de mulheres de duas gerações: "que seja terno enquanto dure". Psicologia Clínica, 22(2), 83-106. doi: 10.1590/S0103-56652010000200007

Diniz Neto, O. D., \& Féres-Carneiro, T. (2010). Construção e dissolução da conjugalidade: Padrões relacionais. Paidéia (Ribeirão Preto), 20(46), 269278. doi: 10.1590/S0103-863X2010000200014
Fleck, M. P. A., Borges, Z. N., Bolognesi, G., \& Rocha, N. S. (2003). Desenvolvimento do WHOQOL, módulo espiritualidade, religiosidade e crenças pessoais. Revista de Saúde Pública, 37(4), 446-455. doi: 10.1590/S0034-89102003000400009

Fonseca, S. R. A., \& Duarte, C. M. N. (2014). Do namoro ao casamento: Significados, expectativas, conflito e amor. Psicologia: Teoria e Pesquisa, 30(2), 135-143. doi: 10.1590/S0102-37722014000200002

Garcia, M. L. T., \& Tassara, E. T. O. (2003). Problemas no casamento: Uma análise qualitativa. Estudos de Psicologia (Natal), 8(1), 127-133.

Karney, B. R., \& Bradbury, T. N. (1995). The longitudinal course of marital quality and stability: A review of theory, method, and research. Psychological Bulletin, 118, 3-34. doi: 10.1037/0033-2909.118.1.3

Landis, M., Peter-Wight, M., Martin, M., \& Bodenmann, G. (2013). Dyadic coping and marital satisfaction of older spouses in long-term marriage. GeroPsych, 26(1), 39-47. doi: 10.1024/1662-9647/a000077

McCullough, M. E., Worthington Junior, E. V., \& Rachal, K. C. (1997). Interpersonal forgiving in close relationships. Journal of Personality and Social Psychology, 73(2), 321-336. doi: 10.1037/0022-3514.73.2.321

Meihy, J. C. S. B. (2006). Os novos rumos da história oral: O caso brasileiro. Revista de História, 155(2), 191-203.

Mosmann, C., \& Falcke, D. (2011). Conflitos conjugais: Motivos e frequência. Revista da SPAGESP, 12(2), 5-16. Recuperado de http://pepsic.bvsalud.org/scielo.php?script $=$ sci_arttext\&pid $=$ S1677-29702011000200002

Norgren, M. B. P., Souza, R. M., Kaslow, F., Hammerschmidt, H., \& Sharlin, S. A. (2004). Satisfação conjugal em casamentos de longa duração: Uma construção possível. Estudos de Psicologia (Natal), 9(3), 575-584. doi: 10.1590/ S1413-294X2004000300020

O'Leary, K. D., Acevedo, B. P., Aron, A., Huddy, L., \& Mashek, D. (2012). Is long-term love more than a rare phenomenon? If so, what are its correlates? Social Psychological and Personality Science, 3(2), 241 249. doi: 10.1177/1948550611417015

Petrican, R., Moscovitch, M., \& Grady, C. (2014). Proficiency in positive vs. negative emotion identification and subjective well-being among long-term 
married elderly couples. Frontiers in Psychology, 5, 1-20. doi: 10.3389/fpsyg.2014.00338

Rosowsky, E., King, K. D., Coolidge, F. L. Rhoades, C. S., \& Segal, D. L. (2012). Marital satisfaction and personality traits in long-term marriages: An exploratory study. Clinical Gerontologist, 35, 77-87. doi: 10.1080/07317115.2011.639855

Rizzon, A. L. C., Mosmann, C. P., \& Wagner, A. (2013). A qualidade conjugal e os elementos do amor: Um estudo correlacional. Contextos Clínicos, 6(1), 41-49. doi: $10.4013 /$ ctc.2013.61.05

Rogers, C. R. (1985). Novas formas do amor: O casamento e suas alternativas. ( $7^{\mathrm{a}}$ ed., O. M. Cajado, Trad.). Rio de Janeiro: José Olympio.

Schlösser, A. (2014). Interface entre saúde mental e relacionamento amoroso: Um olhar a partir da Psicologia Positiva. Pensando Famílias, 18(2), 1733. Recuperado de http://pepsic.bvsalud.org/ scielo.php?script $=$ sci_arttext\&pid $=$ S1679-494X2014000200003

Scorsolini-Comin, F. (2014). Aconselhamento psicológico com casais: Interlocuções entre Psicologia
Positiva e abordagem centrada na pessoa. Contextos Clínicos, 7(2), 192-206. doi: 10.4013/ctc.2014.72.07

Scorsolini-Comin, F., \& Santos, M. A. (2012). Correlations between subjective well-being, dyadic adjustment and marital satisfaction in Brazilian married people. The Spanish Journal of Psychology, 15(1), 166-176. doi: 10.5209/rev_SJOP.2012.v15. $\mathrm{n} 1.37304$

Seligman, M. E. P. (2011). Florescer: Uma nova compreensão sobre a natureza da felicidade e do bem-estar. (C. P. Lopes, Trad.). Rio de Janeiro, Objetiva.

Wagner, A., \& Falcke, D. (2001). Satisfação conjugal e transgeracionalidade: Uma revisão teórica sobre o tema. Psicologia Clínica, 13(2), 1-15. doi: 10.1590/ S0102-37722010000300015

Zordan, E. P., \& Wagner, A. (2009). Projetos vitais de adultos jovens solteiros: Uma reflexão sobre o lugar do casamento. Contextos Clínicos, 2(2), 91-96. doi: $10.4013 /$ ctc.2009.22.03

Recebido em: 22/10/2015

Reformulado em: 28/03/2016 Aceito em: 31/03/2016 
Nota dos autores:

O estudo recebeu o apoio do Conselho Nacional de Desenvolvimento Científico e Tecnológico (CNPq) e da Fundação de Amparo à Pesquisa do Estado de Minas Gerais (FAPEMIG).

Lucio Andrade Silva recebeu bolsa de iniciação científica do Conselho Nacional de Desenvolvimento Científico e Tecnológico (CNPq).

Fabio Scorsolini-Comin recebeu bolsa de Pós-Doutorado Junior do Conselho Nacional de Desenvolvimento Científico e Tecnológico (CNPq - Processo 501391/2013-4). Coordenador de Proposta de Edital de Demanda Universal da Fundação de Amparo à Pesquisa do Estado de Minas Gerais (FAPEMIG).

Manoel Antônio dos Santos recebeu bolsa de Produtividade em Pesquisa do Conselho Nacional de Desenvolvimento Científico e Tecnológico (CNPq-PQ-1B - Processo 307677/2011-7).

Sobre os autores:

Lúcio Andrade Silva é psicólogo pela Universidade Federal do Triângulo Mineiro - UFTM e membro do PROSA Laboratório de Investigações sobre Práticas Dialógicas e Relacionamentos Interpessoais (UFTM-CNPq). Foi bolsista de iniciação científica do CNPq.

E-mail: lucio.andrade.s@hotmail.com

Fabio Scorsolini-Comin é professor adjunto do Departamento de Psicologia e do Programa de Pós-Graduação em Psicologia da Universidade Federal do Triângulo Mineiro - UFTM, doutor em Psicologia pela Faculdade de Filosofia, Ciências e Letras de Ribeirão Preto da Universidade de São Paulo (FFCLRP-USP) e coordenador do PROSA - Laboratório de Investigações sobre Práticas Dialógicas e Relacionamentos Interpessoais (UFTM-CNPq).

E-mail: fabioscorsolini@gmail.com

Manoel Antônio dos Santos é professor associado 3 do Departamento de Psicologia e do Programa de PósGraduação em Psicologia da Faculdade de Filosofia, Ciências e Letras de Ribeirão Preto da Universidade de São Paulo (FFCLRP-USP), bolsista de Produtividade em Pesquisa do CNPq (PQ-1B) e coordenador do Laboratório de Ensino e Pesquisa em Psicologia da Saúde (LEPPS-CNPq-FFCLRP-USP).

E-mail:manoelmasantos@gmail.com

Contato com os autores:

Programa de Pós-graduação em Psicologia, Universidade Federal do Triângulo Mineiro

Rua Conde de Prados, 155

Abadia, Uberaba-MG, Brasil

CEP: $38025-260$ 
